\title{
Políticas de ensino superior e a graduação em Terapia Ocupacional nas Instituiçóes Federais de Ensino Superior no Brasil ${ }^{1}$
}

\author{
Livia Celegati Pan, Roseli Esquerdo Lopes
}

Departamento de Terapia Ocupacional, Universidade Federal de São Carlos - UFSCar, São Carlos, SP, Brasil.

\begin{abstract}
Resumo: Introdução: Programas que integraram políticas de ensino superior recentemente adotadas no Brasil, em especial o Programa de Apoio a Planos de Reestruturação e Expansão das Universidades Federais - REUNI e o Programa Nacional de Reorientação da Formação Profissional em Saúde - Pró-Saúde, promoveram a ampliação de cursos e vagas em Instituições Federais de Ensino Superior (IFES) e o redirecionamento da formação de profissionais que atuam na área da saúde, respectivamente, com implicações também para a formação de terapeutas ocupacionais. Objetivo: O objetivo deste texto é apresentar um panorama dos cursos de graduação em terapia ocupacional das IFES e contextualizar seu processo de implantação no âmbito do REUNI e do Pró-Saúde. Método: A partir do levantamento e da análise dos projetos político-pedagógicos de cada um desses cursos, foram entrevistados seus coordenadores. Resultados: Os resultados apontaram que o REUNI teve um grande impacto na área, tendo sido fundamental para o processo de expansão da graduação em terapia ocupacional no Brasil, principalmente para regiões que, até então, não ofertavam cursos públicos nesse âmbito. Por outro lado, o Pró-Saúde não foi uma presença significativa na grande maioria dos cursos estudados; seus reflexos na área foram indiretos. Conclusão: Os cursos estão em consonância com as Diretrizes Curriculares Nacionais para a graduação em terapia ocupacional; contudo, se evidencia uma necessidade de rediscussão, no interior da profissão, dos elementos que parametrizam essa formação para além do que aparece como central nos discursos e nos documentos, sobretudo, em referência ao posicionamento em torno do que se coloca como um profissional com perfil generalista.
\end{abstract}

Palavras-chave: Formação Profissional Graduada, Ensino Superior, Instituições Federais de Ensino Superior, Programa de Apoio a Planos de Reestruturação e Expansão das Universidades Federais, Programa Nacional de Reorientação da Formação Profissional em Saúde - Pró-Saúde.

\section{Higher education politics and the graduation in Occupational Therapy at the Federal Institutions of Higher Education in Brazil}

\begin{abstract}
Introduction: Programs that integrate higher education policies recently adopted in Brazil, especially the Program of Support for the Restructuring and Expansion of Federal Universities (REUNI) and the Program National for the Reorientation Professional Training in Health (Pró-Sáude), expanded courses and vacancies in Federal Institutions of Higher Education (IFES) and redirected the training of professionals working in the health sector, respectively, with implications also for the formation of occupational therapists. Objective: this article aims to present an overview of graduation courses in occupational therapy from IFES and contextualize the deployment process in the context of the REUNI and the Pró-Sáude. Method: We interviewed the courses coordinators based on the survey and analysis of political-pedagogical projects of each of these courses. Results: The results indicated that the REUNI had a big impact in the area which was fundamental to the expansion process to graduation in occupational therapy in Brazil, especially for regions that had not public courses within that framework until then.
\end{abstract}

Autor para correspondência: Livia Celegati Pan, Laboratório METUIA, Departamento de Terapia Ocupacional, Universidade Federal de São Carlos, Rodovia Washington Luís, Km 235, SP-310, CEP 13565-905, São Carlos, SP, Brasil, e-mail: liviacpan@yahoo.com.br 
On the other hand, the Pró-Saúde has not had a significant impact on the vast majority of courses studied; its effect in the area was indirect. Conclusion: The courses are in agreement with the National Curriculum Guidelines for graduation in occupational therapy, however, becomes evident the need for discussion in the profession the elements that parameterize this formation, beyond that which shows up as central in the speeches and documents, mostly in reference of what is posited as a professional with generalist profile.

Keywords: Professional Training Graduate, Higher Education, Federal Institutions of Higher Education, Program of Support for the Restructuring and Expansion of Federal Universities, Program National for the Reorientation Professional Training in Health-Pró-Sáude.

\section{Introdução}

A partir dos anos 2000, uma série de programas compôs a política de ensino superior no Brasil, com vistas a sua expansão e reestruturação, sendo dois destes o Programa de Apoio a Planos de Reestruturação e Expansão das Universidades Federais (REUNI) e o Programa Nacional de Reorientação da Formação Profissional em Saúde (Pró-Saúde) (CARVALHO, 2006; BRASIL, 2007a, b).

O REUNI, implantado em 2007, esteve destinado especificamente às universidades federais, como uma das açóes consubstanciadas pelo Plano de Desenvolvimento da Educação (PNE), lançado pelo Ministério da Educação (MEC) no mesmo ano. Sua proposta de ampliação de vagas, criação de novos cursos de graduação e de novos campi se deu com base na constatação de algumas problemáticas em torno das Instituiçóes Federais de Ensino Superior (IFES), dentre as quais foram destacadas a ociosidade de espaços físicos, em especial no período noturno; os altos índices de evasão de estudantes nos cursos de graduação; a rigidez dos currículos, e o descompasso com as competências demandadas pelo mercado de trabalho. Além disso, um importante pilar desse programa era o aumento de vagas públicas no sistema federal de ensino superior (CARVALHO, 2006; BRASIL, 2007a).

Já o Pró-Saúde esteve integrado a uma política que procurou reconfigurar o ensino superior na área de saúde por meio de programas indutores ${ }^{2}$ dos Ministérios da Saúde e da Educação (CONTERNO; LOPES, 2013), tendo como objetivo geral transformar os processos tradicionais de formação dos profissionais que atuam no setor saúde, como meio para consolidação e fortalecimento dos princípios do Sistema Único de Saúde (SUS), propondo financiamento para os cursos que optassem por integrar o programa e se propusessem a reformular os seus currículos na direção pretendida (BRASIL, 2007b).

Originário do antigo Programa de Incentivo a Mudanças Curriculares nos Cursos de Medicina (PROMED), o Pró-Saúde teve sua primeira versão em 2005, voltada apenas para os cursos de graduação em medicina, enfermagem e odontologia, e, posteriormente, em 2007, foi ampliado para os demais cursos de graduação da área da saúde, buscando maior integração entre o ensino e o SUS, com ênfase na atenção básica em saúde (BRASIL, 2007b; CONTERNO, 2013).

Para a adesão, era necessário que os cursos reformulassem seus Projetos Político-Pedagógicos no sentido de atender aos eixos propostos pelo programa, os quais orientavam a adoção de determinadas metodologias tidas como "ativas" no processo ensino-aprendizagem, a integração entre os serviços de saúde, com destaque para a rede pública, e as Instituições de Ensino Superior (IES), a inserção dos estudantes em serviços de saúde desde o início do curso, com foco na atenção básica em saúde e prevendo o incentivo à educaçáo permanente (BRASIL, 2007b).

No interior da terapia ocupacional, a preocupação com a qualidade da formação graduada e com o estabelecimento de padróes mínimos comuns tem sido pauta recorrente para os profissionais e, principalmente, para os docentes da área (LOPES, 1991, 2004; HAHN; LOPES, 2003; LOPES et al., 2008).

Internacionalmente, desde a sua fundação, a Federação Mundial de Terapeutas Ocupacionais (World Federation of Occupational Therapists - WFOT) se preocupou com a elaboração de padróes mínimos para a formação de terapeutas ocupacionais. Seu documento mais recente com esse fim, "Padróes para a Educação de Terapeutas Ocupacionais" (Standards for the Education of Occupational Therapists), de 2002 , tem como objetivos estabelecer tais padróes como uma norma e impulsionar o desenvolvimento contínuo da sua qualidade. De acordo com esse documento, o ensino profissional da área deveria englobar perspectivas internacionais, abordando as crenças compartilhadas mundialmente pelos terapeutas ocupacionais, mas também as perspectivas locais, particulares de cada país, e incorporar os campos de trabalho consolidados e que se espera sejam de domínio de um futuro profissional, assim como a maior variedade possível de cenários dentro do que 
vai se constituindo como novas possibilidades de atuação e para as quais a formação deve, igualmente, se voltar. Esses padróes levam em conta a natureza dinâmica dos programas de ensino e as diferenças e particularidades nacionais e regionais (WORLD..., 2002).

No Brasil, as Diretrizes Curriculares Nacionais para o Ensino de Graduação em Terapia Ocupacional (BRASIL, 2002), também de 2002, estabelecem os princípios da formação de terapeutas ocupacionais e são fruto de um longo e intenso processo.

Em 1995, com o texto da Lei de Diretrizes e Bases da Educação Nacional (LDBEN) já definido, apesar da sua aprovaçáo apenas no ano seguinte com a Lei No 9.394, previa-se a extinção da exigência de currículos mínimos pelas IES. A referida lei trazia, entáo, como novos referenciais para os cursos de graduação, as Diretrizes Curriculares Nacionais (DCN), a serem elaboradas com o auxílio de docentes especialistas de cada área. Assim, foi constituída a Comissão de Especialistas de Ensino de Fisioterapia e Terapia Ocupacional, ligada à Secretaria de Ensino Superior do Ministério da Educação (SESu/ MEC), com o objetivo geral de assessoramento nos processos de autorizaçáo e reconhecimento dos cursos de graduação de ambas as áreas e no credenciamento das instituiçôes. Em 1998, esta comissão foi desmembrada em duas, uma para a terapia ocupacional e outra para a fisioterapia (BRASIL, 1996, 1997; HAHN; LOPES, 2003).

No caso da terapia ocupacional, as docentes que integraram essas comissóes ${ }^{3}$ trabalharam, em diferentes períodos, exaustivamente na elaboração de instrumentos capazes de formalizar a estrutura e o funcionamento dos cursos de graduaçáo em terapia ocupacional no país, sempre tomando como referência os padróes internacionais, assim como as discussóes oriundas da articulaçáo coletiva dos docentes e coordenadores de cursos nos encontros nacionais ${ }^{4}$.

Como parte desse trabalho e com a necessidade de elaboração das diretrizes para o ensino em terapia ocupacional, a Comissão de Especialistas de Ensino de Terapia Ocupacional (CEETO) apresentou, no final de 1998, à SESu/MEC, o documento "Proposta de Normatização de Diretrizes Curriculares para os Cursos de Terapia Ocupacional", resultado de um amplo processo de discussáo entre os docentes terapeutas ocupacionais do país, como também com representantes das escolas de terapia ocupacional existentes à época, e que foi consolidado e aprovado no VI Encontro Nacional de Docentes de Terapia Ocupacional, realizado em Gramado-RS (HAHN; LOPES, 2003; REDE..., 1998).

Esse documento propunha uma formação generalista, que contemplasse de forma equilibrada conhecimentos gerais nas áreas biológicas e humanas, e os específicos do campo da terapia ocupacional, estabelecendo, para isso, cargas horárias mínimas, a saber: 360 horas para os conteúdos das áreas biológicas e humanas (cada um) e 2.880 horas para os conteúdos específicos, somando, portanto, uma carga horária mínima de 3.600 horas. Fixava também que os cursos deveriam ter no mínimo 1.000 horas de formação em serviço, atendendo às normas da WFOT. Colocava, ainda, a possibilidade de flexibilização das propostas curriculares pelas IES, desde que assegurados esse equilíbrio e a base nacional comum (BRASIL, 1998).

Apesar de traduzir as aspirações dos terapeutas ocupacionais para a formação profissional na época, a referida proposta não foi aprovada pelo Conselho Nacional de Educaçáo (CNE), que a considerou demasiadamente normativa e não devidamente alinhada à flexibilização curricular estabelecida pela LDBEN.

Em decorrência, iniciou-se uma intensa discussão entre a CEETO e o CNE: de um lado, a CEETO considerava imprescindível o estabelecimento de alguns critérios mínimos considerados necessários para alcançar um patamar inalienável de qualidade na formação, sobretudo a fixação de alguns conteúdos, de carga horária mínima total e de formação em serviço, aspectos até entáo garantidos pelo currículo mínimo, e de outro, o CNE não abria mão da necessidade de flexibilização dos currículos, considerando excessivamente rigorosas as exigências da comissáo, pontuando que o estabelecimento de quaisquer cargas horárias não seria objeto das DCN (LOPES; MAGALHÃES; MAGALHÃES, 2001).

Esse debate se estendeu por pouco mais de três anos, até a elaboração do texto final das DCN para a graduação em terapia ocupacional e, apesar da postura pouco flexível do CNE, a CEETO conseguiu incorporar ao texto final a maior parte das competências e habilidades específicas estabelecidas na primeira proposta elaborada. No entanto, a resolução final não abarcou parte dos interesses colocados como essenciais, fundamentalmente o estabelecimento de cargas horárias mínimas totais ou parciais (LOPES; MAGALHÃES; MAGALHÃES, 2001; HAHN; LOPES, 2003; LOPES, 2004).

A recente e grande expansão de vagas e cursos públicos de graduação em terapia ocupacional no Brasil, notadamente nas IFES, traz consigo questôes a serem discutidas, sendo uma destas como esses novos cursos estão se desenvolvendo.

$\mathrm{O}$ intuito deste artigo, que decorre de uma pesquisa mais ampla que integra uma Dissertação de Mestrado, é apresentar um panorama dos cursos de graduação em terapia ocupacional das IFES, além 
de contextualizar seu processo de implantação no âmbito do REUNI e do Pró-Saúde.

\section{Método}

Partiu-se da proposição de um estudo exploratório que trouxesse subsídios para a compreensão da constituição do quadro atual dos cursos de graduação em terapia ocupacional, tomando-se o caso das IFES.

A coleta de dados se deu no período entre os anos de 2012 e 2013.

Inicialmente, realizou-se um levantamento junto ao Instituto Nacional de Estudos e Pesquisas Educacionais Anísio Teixeira acerca dos cursos de graduação em terapia ocupacional em funcionamento no país, no ano de 2012. Em seguida, classificaram-se os cursos quanto ao tipo de IES a que estavam vinculados: privada, pública estadual e pública federal, chegando-se ao total de 15 cursos de graduação em terapia ocupacional ligados às IFES.

Contatou-se cada um dos coordenadores desses cursos, a fim de se explicitarem os objetivos da pesquisa e convidá-los à colaboração por meio da disponibilização da documentação pertinente e da concessáo de uma entrevista. Todos aceitaram o convite, formalizado por um termo de consentimento.
Feito o levantamento documental dos projetos político-pedagógicos em vigência de cada um dos cursos de graduação em terapia ocupacional das IFES, a partir de um roteiro comum, procedeu-se à entrevista com todos os seus coordenadores, na qual foram abordados aspectos particulares relativos ao curso, em especial seu histórico e a construção do projeto político-pedagógico em vigor. $\mathrm{Na}$ entrevista, também foram tratadas as especificidades da caracterização dos cursos, em termos de objetivos, matriz curricular, perfil do profissional a ser formado, apontamentos presentes e suas condiçóes de desenvolvimento.

As elaborações que se seguem decorrem desse conjunto de dados.

\section{Resultados e Discussão}

\subsection{Os cursos de graduação em Terapia Ocupacional das IFES}

De acordo com os dados do INEP, em 2013, havia 63 cursos de graduação em terapia ocupacional em funcionamento no país, sendo 21 em IES pública e 42 em IES privada. Dentre os cursos públicos, 15 eram de IFES (INSTITUTO..., 2013).

A seguir, a Tabela 1 apresenta de modo geral os cursos de graduação em terapia ocupacional das IFES:

Tabela 1. Panorama geral dos cursos de graduação em terapia ocupacional das IFES - 2013.

\begin{tabular}{|c|c|c|c|c|c|}
\hline \multirow{3}{*}{ IFES* } & \multirow{3}{*}{$\begin{array}{c}\text { Ano de Criação } \\
\text { do Curso }\end{array}$} & \multirow{3}{*}{$\begin{array}{c}\text { Projeto } \\
\text { Político- } \\
\text { Pedagógico } \\
\text { Vigente }\end{array}$} & \multicolumn{3}{|c|}{ Recursos Humanos } \\
\hline & & & \multicolumn{2}{|c|}{$\mathbf{N}^{o}$ de Docentes** } & \multirow[b]{2}{*}{ Técnicos } \\
\hline & & & Efetivos & $\begin{array}{l}\text { Substitutos/ } \\
\text { Temporários }\end{array}$ & \\
\hline UFPE & 1962 & 2011 & 18 & 2 & - \\
\hline UFSCar & 1978 & 2011 & 17 & 11 & - \\
\hline UFMG & 1979 & 2009 & 17 & 2 & - \\
\hline UFPR & 2000 & 2005 & 23 & - & 2 \\
\hline UNIFESP & 2006 & 2013 & 14 & - & - \\
\hline UFTM & 2007 & 2007 & 15 & 4 & 2 \\
\hline UnB & 2008.2 & 2009 & 12 & 2 & - \\
\hline UFPA & 2009 & 2009 & 6 & 2 & - \\
\hline UFES & 2009 & 2007 & 12 & - & 2 \\
\hline IFRJ & 2009 & 2012 & 9 & 3 & - \\
\hline UFRJ & 2009.2 & 2008 & 15 & 10 & - \\
\hline UFSM & 2009.2 & 2009 & 9 & - & - \\
\hline UFPB & 2010.2 & 2008 & 12 & - & - \\
\hline UFPel & 2010.2 & 2013 & 2 & 6 & - \\
\hline UFS & 2011 & 2012 & 8 & 2 & - \\
\hline Totais & & & 189 & 44 & $6^{* * *}$ \\
\hline
\end{tabular}

*Todas oferecem cursos em período integral, com exceção do Curso de Graduação em Terapia Ocupacional da UFPR, que possui uma entrada em período integral e uma entrada em período noturno. **Considerando apenas os da Área Específica Terapia Ocupacional. ***Terapeutas ocupacionais. Fonte: Projetos Político-Pedagógicos e Entrevistas com Coordenadores dos Cursos de Graduação em Terapia Ocupacional das IFES; elaboração das autoras. 
Observa-se que, por um longo período, entre as décadas de 1960 e 2000, existiam poucos cursos de graduação em terapia ocupacional em IFES e que a maioria foi criada após 2006, com intensa abertura de novos cursos nos anos de 2009 e 2010. Isso se deu pela implementaçáo do REUNI, o que se discutirá posteriormente.

Há uma variação em relação ao número de vagas oferecidas anualmente, sendo que, nos cursos que oferecem maior quantidade de vagas, ocorre mais de uma entrada por ano.

Da mesma forma, varia o número de recursos humanos específicos da área dedicados à formação. Cabe destacar que todos os novos cursos criados por meio do REUNI ainda não estavam com o seu corpo docente completo 5 . Um fator apontado como limitante pelos coordenadores entrevistados foi a falta de contrataçáo de terapeutas ocupacionais para atuarem como técnicos nos cursos e que eles assumissem a tarefa de implementação, acompanhamento e supervisão da prática profissional, o que vem implicando em acúmulo de funçóes para os docentes. Igualmente, todos os coordenadores consideraram o número de recursos humanos insuficiente, o que influiria diretamente na qualidade não apenas do ensino, mas também no desenvolvimento de atividades de pesquisa e extensão.

Todos os projetos político-pedagógicos analisados foram elaborados tendo como referencial as DCN para a graduaçáo em terapia ocupacional de 2002 e, de uma forma geral, seus textos estão em consonância com o que está estabelecido por essas diretrizes no âmbito nacional, enfatizando, principalmente, a proposição de uma formação crítica, humanista, reflexiva e generalista.

No que concerne à matriz curricular dos cursos, em termos de cargas horárias e sua distribuição, os dados estáo sintetizados na Tabela 2.

Não há uma uniformidade nos cursos no que tange à carga horária total; no entanto, na maioria deles, esta é superior a 3.600 horas, número mínimo defendido pelos docentes terapeutas ocupacionais durante o processo de construção das DCN. As exceçóes são os cursos da UnB, UFRJ, UFPB e UFMG, sendo que este último sequer atinge a carga horária mínima de 3.240 horas fixada pelo antigo currículo mínimo, de 1983.

Quantidade não se transforma necessariamente em qualidade, contudo, qualidade implica alguma quantidade mínima; apesar de a carga horária mínima não estar fixada nas DCN e de o CNE ter definido esse mínimo em 3.200 horas (BRASIL, 2009), há parâmetros consensuados, nacional e internacionalmente, no interior da categoria profissional e que devem ser levados em conta no processo de construçáo de um curso de graduação (WORLD..., 2002; HAHN; LOPES, 2003).

Embora legalmente as DCN sejam o norteador da formação de terapeutas ocupacionais no Brasil, observa-se que boa parte dos cursos tem optado e conseguido levar em conta não apenas o que estas

Tabela 2. Síntese das matrizes curriculares dos cursos de graduação em terapia ocupacional das IFES - 2013.

\begin{tabular}{ccccccccc}
\hline IFES & $\begin{array}{c}\text { Tempo } \\
\text { Mínimo de } \\
\text { Integralização }\end{array}$ & $\begin{array}{c}\text { CH Total } \\
\text { (em horas) }\end{array}$ & $\begin{array}{c}\text { CH } \\
\text { Específica }\end{array}$ & $\begin{array}{c}\text { CH } \\
\text { CBS }\end{array}$ & $\begin{array}{c}\mathbf{C H} \\
\mathbf{C S H}\end{array}$ & $\begin{array}{c}\mathbf{C H} \\
\text { Pesquisa }\end{array}$ & $\begin{array}{c}\mathbf{C H} \\
\text { Optativa }\end{array}$ & $\begin{array}{c}\text { Atividade } \\
\text { Complementar } \\
\text { (em horas) }\end{array}$ \\
\hline UFPE & 4 anos & 3600 & $64 \%$ & $23 \%$ & $8 \%$ & $3 \%$ & $2 \%$ & 150 \\
UFSCar & 5 anos & 4300 & $*$ & $*$ & $*$ & $*$ & $*$ & 100 \\
UFMG & 4 anos & 3060 & $56 \%$ & $19 \%$ & $11 \%$ & $8 \%$ & $6 \%$ & 180 \\
UFPR & 4,5 anos & 3855 & $60 \%$ & $25 \%$ & $12 \%$ & $3 \%$ & - & 180 \\
UNIFESP & 4 anos & 4540 & $59 \%$ & $31 \%$ & $6 \%$ & $4 \%$ & - & 200 \\
UFTM & 4 anos & 3920 & $62 \%$ & $21 \%$ & $10 \%$ & $4 \%$ & $3 \%$ & 335 \\
UnB & 4 anos & 3570 & $43 \%$ & $23 \%$ & $7 \%$ & $3 \%$ & $24 \%$ & 150 \\
UFPA & 5 anos & 3750 & $46 \%$ & $41 \%$ & $7 \%$ & $4 \%$ & $2 \%$ & 300 \\
UFES & 4 anos & 3995 & $67 \%$ & $15 \%$ & $9 \%$ & $4 \%$ & $5 \%$ & 200 \\
IFRJ & 4 anos & 4407 & $57 \%$ & $27 \%$ & $9 \%$ & $3 \%$ & $4 \%$ & 297 \\
UFRJ & 4 anos & 3450 & $63 \%$ & $19 \%$ & $10 \%$ & $4 \%$ & $4 \%$ & 200 \\
UFSM & 4 anos & 4090 & $62 \%$ & $23 \%$ & $9 \%$ & $2 \%$ & $4 \%$ & 280 \\
UFPb & 4 anos & 3390 & $58 \%$ & $15 \%$ & $11 \%$ & $6 \%$ & $10 \%$ & $*$ \\
UFPel & 4 anos & 4097 & $* *$ & $* *$ & $* *$ & $* *$ & $* *$ & $*$ \\
UFS & 4 anos & 3600 & $57 \%$ & $29 \%$ & $7 \%$ & $5 \%$ & $2 \%$ & 180 \\
\hline
\end{tabular}

CH: Carga Horária. CBS: Ciências Biologias e da Saúde. CSH: Ciências Sociais e Humanas. *Dados não disponíveis no Projeto Político-Pedagógico. **Projeto Político-Pedagógico não acessado. Fonte: Projetos Político-Pedagógicos dos Cursos de Graduação em Terapia Ocupacional das IFES; elaboração das autoras. 
estabelecem, mas, também, o que está acordado no interior da categoria profissional como padrão mínimo de qualidade para a formação, que, na ausência de discussôes atuais, permanece sendo aquele primeiro documento apresentado pela CEETO ao Ministério da Educação, em 1998, com exceção da questão da carga horária mínima defendida, que passou de 3.600 para 4.000 horas (REDE..., 2008).

Quanto à divisão da carga horária total pelas áreas de conhecimento, todos os cursos possuem basicamente a mesma estrutura, sendo, quantitativamente, de modo decrescente: conteúdos específicos da terapia ocupacional, conteúdos das ciências biológicas e da saúde, das ciências sociais e humanas, e, de forma mais igualitária, conteúdos ligados ao campo da pesquisa e optativos. A única exceção é o Curso de Graduação em Terapia Ocupacional da UnB, que possui uma elevada porcentagem de conteúdos optativos.

Nota-se uma porcentagem elevada de conteúdos ligados às ciências biológicas e da saúde, e uma distribuição desproporcional quando comparados aos conteúdos das ciências sociais e humanas, sendo mais ou menos acentuada, a depender do curso. Ainda, ao analisar os conteúdos das ciências biológicas e da saúde, verifica-se que grande parte das disciplinas é essencialmente médico-biológica.

Sem dúvida, o conhecimento e o entendimento de alguns processos biológicos são necessários para o exercício da terapia ocupacional, porém, é preciso que se discutam quais desses conteúdos são realmente indispensáveis e qual deve ser o seu nível de aprofundamento, uma vez que a terapia ocupacional é definida como um campo de conhecimento e intervenção em saúde, em educação e no campo social, que visa, através de suas açóes, a emancipação e a autonomia de pessoas que, por razōes ligadas a problemáticas específicas, apresentam, temporária ou definitivamente, dificuldades de inserçáo e participação na vida social (CENTRO..., 1997). Apesar de algumas dessas problemáticas envolverem disfunçôes biológicas, a terapia ocupacional não estabelece açốes relacionadas à cura.

É necessário que se problematize o modo como esses conteúdos são abordados na graduaçáo, com vistas à total superação do modelo biomédico hegemônico. Conforme Soares (1991), esse fato, que tem raízes na história da terapia ocupacional brasileira e resulta de um movimento de alinhamento aos preceitos desse modelo que buscava a validação técnica e científica da profissáo, dentro de uma visáo reducionista da acepção tanto do papel do técnico quanto do que fosse significativo academicamente. As implicaçôes disso se fazem sentir ainda hoje, quando da necessidade da terapia ocupacional ser enquadrada enquanto uma profissão exclusivamente "da saúde", o que pode ser compreendido como um meio de legitimar a sua prática, alcançar reconhecimento e/ou construir uma determinada identidade profissional.

No que concerne à formação específica em terapia ocupacional, apesar de em todos os cursos a carga horária a ela destinada ocupar a maior parte do currículo, também não há uniformidade quanto à porcentagem que representam, variando entre $43 \%$ e $67 \%$. O panorama dessa formaçáo nos cursos se colocou da seguinte forma:

Constata-se, no que diz respeito à formação específica, que os conteúdos de ordem prática são o foco, como, aliás, sempre foram, quando náo foram únicos, na história da formação em terapia ocupacional (LOPES, 2004), possuindo maior carga horária que os conteúdos teóricos, excetuando-se o curso da UFTM, em que essa situação se inverte.

Como já mencionado, no Brasil não há fixação de cargas horárias mínimas também quanto a esse aspecto; entretanto, os Padróes para a Educação de Terapeutas Ocupacionais, da WFOT, recomendam 1.000 horas mínimas de formação em serviço (WORLD..., 2002). O que se pode notar, pela Tabela 3, é que alguns cursos não atingem esse padrão mínimo.

Em relação às subáreas de atuaçáo profissional da terapia ocupacional propostas para a formaçáo nos cursos estudados, em todos estes, a maior parte dessas subáreas, ou até sua totalidade, está ligada ao setor saúde, especialmente à atuação especializada de média complexidade, mas com ênfase crescente na atenção primária à saúde, conforme seus coordenadores.

Tais dados colocam em pauta o questionamento do que significa, para a terapia ocupacional, um perfil profissional generalista. Embora historicamente o setor saúde tenha sido o de maior absorção de terapeutas ocupacionais, a sua atuaçáo profissional não está restrita a ele e, atualmente, tem se expandido ainda mais. Estabelece-se, como um dos objetivos centrais dos cursos de graduaçáo, a formação de profissionais com um perfil generalista; contudo, é preciso que se discuta e se reflita sobre o que se quer, de fato, com esse preceito.

\subsection{O rebatimento do REUNI e do Pró-Saúde para os cursos de graduação em Terapia Ocupacional das IFES}

Até 2008, havia apenas seis cursos de graduação em terapia ocupacional em IFES; com o REUNI, esses cursos tiveram a expansão no número de vagas oferecidas, como mostra a Tabela 4. 
Tabela 3. Formação específica em terapia ocupacional nos cursos de graduação em terapia ocupacional da IFES, em horas - 2013.

\begin{tabular}{cccc}
\hline IFES & $\begin{array}{c}\text { CH } \\
\text { Específica Total }\end{array}$ & $\begin{array}{c}\text { CH } \\
\text { Específica Teórica }\end{array}$ & $\begin{array}{c}\text { CH } \\
\text { Específica Prática }\end{array}$ \\
\hline UFPE & 2295 & 750 & 1545 \\
UFSCar & $*$ & $*$ & $*$ \\
UFMG & 1710 & 765 & 945 \\
UFPR & 2205 & 780 & 1425 \\
UNIFESP & 2560 & 1038 & 1522 \\
UFTM & 2250 & 1200 & 1050 \\
UnB & 1470 & 540 & 930 \\
UFPA & 1725 & $*$ & $*$ \\
UFES & 2535 & 990 & 1545 \\
IFRJ & 2460 & 885 & 1575 \\
UFRJ & 2050 & 655 & 1395 \\
UFSM & 2475 & 780 & 1695 \\
UFPb & 1965 & $*$ & $*$ \\
UFPel & $* *$ & $* *$ & $*$ \\
UFS & 2052 & $*$ & $*$ \\
\hline
\end{tabular}

*Dados não disponíveis no Projeto Político-Pedagógico. **Projeto Político-Pedagógico não acessado. Fonte: Projetos PolíticoPedagógicos dos Cursos de Graduação em Terapia Ocupacional das IFES; elaboração das autoras.

Tabela 4. Expansão do número de vagas nos cursos de graduação em terapia ocupacional existentes nas IFES, a partir de 2008.

\begin{tabular}{|c|c|c|}
\hline IFES & $\begin{array}{c}\mathrm{N}^{\circ} \text { de vagas oferecidas } \\
\text { antes do REUNI }\end{array}$ & $\begin{array}{c}\mathbf{N}^{\circ} \text { de vagas oferecidas } \\
\text { após o REUNI }\end{array}$ \\
\hline Universidade Federal de Pernambuco & 30 & 36 \\
\hline Universidade Federal de São Carlos & 30 & 40 \\
\hline Universidade Federal de Minas Gerais & 60 & 66 \\
\hline Universidade Federal do Paraná & 30 & 120 \\
\hline Universidade Federal de São Paulo & 30 & 40 \\
\hline Universidade Federal do Triângulo Mineiro & 40 & 60 \\
\hline Total & 220 & 362 \\
\hline
\end{tabular}

Fonte: Coordenadores dos Cursos de Graduação em Terapia Ocupacional das IFES; elaboração das autoras.

Os cursos de graduação em terapia ocupacional de IFES já existentes, até 2008 , somavam uma oferta total de 220 vagas por ano. Após a adesão dessas IFES ao REUNI, esses cursos passaram a totalizar 362 vagas anuais, o que representou um aumento de $64,5 \%$ na oferta de vagas.

Ainda com o REUNI, oito novos cursos de graduação em terapia ocupacional foram criados no país em universidades federais ${ }^{6}$, como explicitado na Tabela 5.

Foram criadas, com o REUNI, 460 novas vagas públicas federais em novos cursos de graduação em terapia ocupacional, no Brasil. Percebe-se também que houve uma expansão para regióes do país que ainda não possuíam cursos na área em IES pública, apesar de estes continuarem escassos, notadamente nas Regiooes Norte e Centro-Oeste.

Para a grande maioria dos coordenadores e representantes dos novos cursos de graduação em terapia ocupacional entrevistados, se não fosse pela adesão de suas instituiçôes ao REUNI, a possibilidade de abertura de tais cursos seria pequena ou até mesmo não existiria. Desse modo, pode-se afirmar que esta política foi determinante para a atual expansão da terapia ocupacional no Brasil.

No entanto, a implantação e a implementação do REUNI nas instituiçóes aqui estudadas não se deram de forma uniforme.

Esse programa previa o investimento de recursos nas universidades federais que aderissem ao programa, com a criaçáo de novos cursos e/ou expansão de vagas em cursos já existentes, ficando a gestão desses recursos a cargo de cada instituição (BRASIL, 2007a). De acordo com o depoimento dos entrevistados, a gestão dos recursos financeiros e humanos providos pelo REUNI se deu de forma diferente entre as universidades aqui estudadas, o que pode justificar algumas condiçóes pouco 
Tabela 5. Novos cursos de graduação em terapia ocupacional criados pelo REUNI.

\begin{tabular}{lc}
\hline \multicolumn{1}{c}{ IFES } & $\mathbf{N}^{\mathbf{o}}$ de vagas atualmente oferecidas \\
\hline Universidade de Brasília & 100 \\
Universidade Federal do Pará & 30 \\
Universidade Federal do Espírito Santo & 50 \\
Universidade Federal de Santa Maria & 70 \\
Universidade Federal do Rio de Janeiro & 60 \\
Universidade Federal da Paraíba & 60 \\
Universidade Federal de Pelotas & 40 \\
Universidade Federal de Sergipe & 50 \\
Total & 460 \\
\hline
\end{tabular}

Fonte: Coordenadores dos Cursos de Graduação em Terapia Ocupacional das IFES; elaboração das autoras.

favoráveis para o desenvolvimento dos novos cursos implantados, âmbito no qual a terapia ocupacional se insere, talvez porque náo fossem mesmo suficientes ou porque o investimento nos novos cursos não tenha sido prioridade, visto que a alocação efetiva desses recursos recebidos é parte da autonomia de cada uma das IFES.

A maior queixa dos coordenadores e representantes dos cursos de graduação em terapia ocupacional estudados é com relação à falta de recursos humanos, especialmente de docentes. Vale salientar que a relação do número de alunos por docente prevista, de modo geral, pelo REUNI, foi de 18 por um (BRASIL, 2007a), e também que o corpo docente dos novos cursos, em sua maioria, não estava completo, havendo previsão de abertura de novos concursos.

De qualquer forma, o que se viu foi que a contratação de docentes para os cursos de graduação em terapia ocupacional nas IFES não tem sido suficiente para acompanhar a ampliação no número de vagas e para possibilitar um pleno desenvolvimento dos seus projetos, ressaltando-se o fato de que a função docente não é "apenas” o ensino de graduação.

Quanto à questão da infraestrutura e dos recursos materiais para o funcionamento desses cursos, quase a totalidade dos sujeitos entrevistados relatou algum tipo de dificuldade, o que, como já dito, parece articular-se à gestão dos recursos financeiros por parte das IFES. Apesar disso, os cursos têm conseguido se desenvolver, sendo realmente o maior problema apontado a falta de recursos humanos.

Isso tem relaçáo com a proposta de melhor aproveitamento da estrutura universitária e obtenção de maior eficiência trazida pelo REUNI, focando em resultados que, náo necessariamente, implicariam em determinada qualidade (ARAÚJO; PINHEIRO, 2010). Seria importante tentar ir além da democratização e ampliação de acesso ao ensino superior.
Não obstante, para a terapia ocupacional no Brasil, uma profissão pouco reconhecida e que até então contava com poucos cursos de graduação, se comparados a outras profissóes, os benefícios trazidos pelo REUNI são claros. Sem esta proposta, certamente, não teríamos o número de cursos públicos que temos?

Contudo, não foram poucas as críticas recebidas por esse programa. Já na época da criação do REUNI, estudiosos da educação superior brasileira afirmaram que, nos moldes em que a expansão pretendida se colocava, não havia uma contrapartida orçamentária correspondente para a implantação de ensino de qualidade. O reflexo disso, primeiro, tem sido a precarização do trabalho docente, com o aumento de alunos sob sua responsabilidade e, ainda, a necessidade de sua maior dedicação a atividades ligadas à graduação, o que pode comprometer atividades de pesquisa e extensão, e, consequentemente, o tripé de sustentação da universidade: ensino-pesquisa-extensão (LÉDA; MANCEBO, 2008).

O que é também preocupante para a terapia ocupacional, que depende do seu avanço científico, por meio da pesquisa, para sua plena institucionalização acadêmica no Brasil, notadamente com a implantação de programas de pós-graduação stricto sensu (LOPES et al., 2014).

$\mathrm{Na}$ época, segundo Catani (2008), uma das únicas possibilidades de obtenção de recursos adicionais pelas universidades federais se deu por meio da sua adesão ao REUNI. Nas palavras do autor: "é ruim se aderir; se não aderir pode ser pior" (CATANI, 2008 , p. 8), o que acabou culminando na elaboração de planos de reestruturaçáo e expansão por todas elas. Isso vai ao encontro dos depoimentos dos coordenadores entrevistados, para os quais o processo de adesão ao REUNI parece ter levado grande parte das instituiçôes a buscar maiores recursos, o que pode ter contribuído para uma democratização do acesso 
ao ensino superior no país, mesmo que relativa, com perda de qualidade desse ensino nas IFES.

Ainda, esse fato coloca uma questão para a expansão de cursos e vagas na área de terapia ocupacional, qual seja: a direção das IFES em que isso aconteceu estava mobilizada por essa expansão, compreendendo sua necessidade frente a demandas sociais para as quais o terapeuta ocupacional se volta, ou foi parte de uma estratégia das justificativas postas para a ampliação de recursos prevista pelo programa? Afinal, todas essas IFES (com exceção do IFRJ), tinham larga tradição no ensino superior em seus estados.

No mais, o REUNI esteve limitado à previsão orçamentária concedida, sendo que os recursos acordados só foram liberados plenamente durante 2013 e estáo ainda sendo implementados. Resta avaliar aonde se chegou com o que foi proposto pelo programa e aceito pelas IFES. O que podemos afirmar, até o momento, é que, sem dúvida, se ampliou o acesso ao ensino superior no Brasil como um todo e, inclusive, para a terapia ocupacional.

Em relação ao Pró-Saúde, esta pesquisa verificou que esse programa não teve impacto direto na elaboração dos atuais projetos político-pedagógicos dos cursos de graduação em terapia ocupacional das IFES. Dos 15 cursos estudados, apenas dois aderiram ao Pró-Saúde com a submissão de propostas e a reformulação do que propunham para a formaçáo graduada, adequando-a às diretrizes do programa. Estes cursos foram os da Universidade Federal de São Carlos e Universidade Federal de Minas Gerais.

$\mathrm{O}$ que as coordenadoras desses cursos apontaram foi que já havia discussões internas com o intuito de reformulaçáo dos antigos projetos político-pedagógicos e muito do que se pretendia ia ao encontro das propostas do Pró-Saúde. Assim, as reformulaçóes não foram realizadas especificamente para atender ao programa; foram processos que caminharam paralelamente e que se encontraram principalmente pela possibilidade de financiamentos propostos. Dentre os demais cursos de graduaçáo em terapia ocupacional estudados, alguns passaram por um processo recente de reformulaçáo dos seus projetos político-pedagógicos e outros, de acordo com os seus coordenadores, pretendem fazê-lo, trazendo em suas novas propostas curriculares consonâncias com as diretrizes do Pró-Saúde, especialmente no que diz respeito à inserção dos alunos nos serviços de atenção básica à saúde desde o início da graduação. Todavia, ao que parece, esses cursos não tiveram acesso a esse programa e a suas possibilidades de financiamento.
Por outro lado, o Programa de Educaçáo pelo Trabalho para a Saúde (PET-Saúde), direcionado para o fortalecimento de áreas estratégicas do SUS, estabelecido como uma das estratégias do Pró-Saúde, dentro do pressuposto da educação pelo trabalho, e que trabalhou com a disponibilizaçáo de bolsas para docentes (tutores), profissionais dos serviços (preceptores) e estudantes de graduação da área da saúde (BRASIL, 2010), teve maior repercussão.

Todos os cursos de graduação em terapia ocupacional das IFES estavam, de alguma forma, envolvidos com o PET-Saúde, com a inserção de alunos e docentes nesses programas em suas instituiçôes. Porém, não foi observada, naquele momento, uma interferência direta também desse programa nos projetos político-pedagógicos dos cursos de graduação em terapia ocupacional, analisados por esta pesquisa.

Esses dados corroboram com os apontamentos feitos por Conterno (2013), de que tais programas, Pró-Saúde e PET-Saúde, possuem um caráter de efeito demonstrativo, ou seja, na medida em que não há incentivos financeiros suficientes para todas as IES interessadas em integrá-los, privilegiam-se algumas instituiçóes de referência e destaque no cenário nacional para que as mudanças na formação profissional promovidas por elas incentivem e sirvam de modelos às demais.

$\mathrm{Na}$ medida em que esses programas surgem com o rótulo de medidas inovadoras - principalmente ao propor a adoçáo de metodologias ativas de ensino-aprendizagem, o que, de fato, não são, como também demonstrado por Conterno (2013) - e com promessas de revolucionar a formação profissional e a assistência à saúde, parecem provocar um "efeito manada” entre os cursos de graduação, que adotam as suas diretrizes, mesmo não estando efetivamente inseridos nos programas, visto que não é desejável não acompanhar a tendência, especialmente se praticada por IES que são referência no ensino da área.

O movimento pela necessidade de reorientaçáo da formação dos profissionais da saúde iniciado principalmente com o PROMED e que culminou na proposição do Pró-Saúde II:

Tornou-se difusor da ideia de que a solução dos problemas da população passaria pela inovação do processo de formaçáo dos profissionais que atuam na área da saúde, ignorando que os problemas de saúde da populaçấo não são exclusivamente resultado da má formação dos seus profissionais, mas sim, da inexistência de acesso aos serviços e aos cuidados à saúde (CONTERNO, 2013, p. 106). 
Não desconsiderando a importância e a necessidade de melhor qualificação profissional para a melhoria da assistência à saúde da população, é essencial o entendimento de que a mudança, por si só, não resulta automaticamente na soluçáo dos problemas do sistema de saúde nacional; mais do que isso, é primordial a existência de condições concretas, ou seja, uma estrutura que proporcione a atuação qualificada, em todo o seu potencial. Para além da questão da formação profissional, é necessária a discussão sobre os elementos determinantes envolvidos na assistência à saúde, como consequências do modelo adotado e das suas formas de financiamento, tendo em vista que o nosso sistema de saúde sofre com determinantes estruturais que ultrapassam os limites de possíveis medidas educacionais (CONTERNO, 2013).

Ademais, o fato de o Pró-Saúde ser uma ampliação do antigo PROMED traz questionamentos quanto ao que se quer efetivamente lidar no âmbito da problemática da formaçáo de profissionais para atuarem na área da saúde, pois as suas diretrizes, idênticas entre os dois programas, parecem estar muito mais vinculadas ao diagnóstico em torno das insuficiências da formação graduada em medicina, não correspondendo, necessariamente, à realidade de formaçáo dos demais cursos da área, como, por exemplo, da terapia ocupacional.

\section{Conclusão}

O Programa de Apoio a Planos de Reestruturação e Expansão das Universidades Federais (REUNI) foi determinante para a expansão dos cursos de graduação em terapia ocupacional em Instituiçóes Federais de Ensino Superior (IFES). Sem a oportunidade proporcionada por esse programa, certamente os oito novos cursos não teriam sido criados.

Se uma das metas da terapia ocupacional para o seu crescimento no país era a criação de mais vagas e novos cursos públicos de graduaçáo, isso foi alcançado. A luta agora deve ser para que esses cursos se consolidem e se desenvolvam com qualidade.

Conforme seus coordenadores, os cursos de graduaçáo em terapia ocupacional aqui estudados vêm enfrentando algumas dificuldades para o seu pleno desenvolvimento, o que se agrava no caso dos novos cursos. Faltam recursos financeiros, materiais e infraestrutura; todavia, parece ser possível conviver e prosseguir com essas questóes. O problema principal está relacionado aos recursos humanos, pois o número atual de docentes e de técnicos da área de todos os cursos é insuficiente para a plena realização das propostas pedagógicas, o que acaba por dificultar a formação graduada, bem como por interferir negativamente nas atividades de pesquisa e extensão.

Para se alcançar o reivindicado e defendido pela terapia ocupacional brasileira, é necessário, além de recursos financeiros, estruturais e materiais, o investimento em recursos humanos, tanto no que concerne à quantidade como à sua maior titulaçáo e/ou capacitaçáo para a realização de pesquisas específicas, visto que ainda há carência de doutores, que têm autonomia para a proposição de pesquisas aos órgãos de fomento.

Também a maneira como se tem estruturado e efetivado a formação profissional deve ser pauta dos debates atuais.

A configuração e a elaboração dos projetos político-pedagógicos dos cursos de graduação em terapia ocupacional das IFES são muito similares e isso, de certo modo, acarretou limites para o aprofundamento das questôes colocadas por esta pesquisa.

Todos os cursos de graduação em terapia ocupacional das IFES, no nível do "discurso" dos seus projetos político-pedagógicos, estão em consonância com as DCN para a graduaçáo na área, especialmente no que diz respeito à proposição de uma formação crítica, humanista, reflexiva e generalista, o que é repetido integralmente em todos eles. Mas, em alguns casos, esses conceitos aparecem esvaziados de contexto e sentido, sem que os conteúdos curriculares façam, verdadeiramente, uma articulação com esses objetivos.

A rediscussão desses preceitos no interior da terapia ocupacional é urgente, sobretudo em referência ao seu posicionamento em torno do que se espera de um profissional generalista.

Os direcionamentos dados para a formaçáo de profissionais para atuarem no setor da saúde, desde a década de 2000 e, posteriormente, mais fortemente com o Pró-Saúde, têm tido implicaçôes restritivas para a graduação em terapia ocupacional.

De um lado, as diretrizes políticas do Ministério da Saúde norteiam e delimitam cada vez mais a formação no âmbito da saúde, ainda que em contradiçáo com as propostas de flexibilização curricular postas pelas próprias DCN; de outro lado, a terapia ocupacional continua expandindo seus contornos e se legitimando progressivamente em outros setores de atuação. Cabe salientar que as competências e habilidades específicas prescritas para a formação do terapeuta ocupacional incluem outros campos, explicitamente. 


\section{Agradecimentos}

Agradecemos a todos os coordenadores dos cursos de graduação em terapia ocupacional das Instituiçôes Federais de Ensino Superior que se disponibilizaram e contribuíram para a realização desta pesquisa.

\section{Referências}

ARAÚJO, M. A. D.; PINHEIRO, H. D. Reforma gerencial do Estado e rebatimentos no sistema educacional: um exame do REUNI. Ensaio: Avaliação e Polititicas Públicas em Educação, Rio de Janeiro, v. 18, n. 69, p. 647-668, 2010.

BRASIL. Conselho Nacional de Educação. Resolução no 4, de 6 de abril de 2009. Dispóe sobre carga horária mínima e procedimentos relativos à integralização e duração dos cursos de graduação em Biomedicina, Ciências Biológicas, Educaçấo Física, Enfermagem, Farmácia, Fisioterapia, Fonoaudiologia, Nutrição e Terapia Ocupacional, bacharelados, na modalidade presencial. Diário Oficial [da] República Federativa do Brasil, Brasília, DF, 7 abr. 2009. Disponível em: <http://portal.mec.gov.br/ dmdocuments/rces004_09.pdf>. Acesso em: 15 mar. 2016.

BRASIL. Lei no 11.892, de 29 de dezembro de 2008. Institui a Rede Federal de Educação Profissional, Científica e Tecnológica, cria os Institutos Federais de Educação, Ciência e Tecnologia, e dá outras providências. $D i-$ ário Oficial [da] República Federativa do Brasil, Brasília, DF, 30 dez. 2008. Disponível em: <http://reitoria.ifpr. edu.br/wp-content/uploads/2009/04/lei_118922.pdf>. Acesso em: 15 mar. 2016.

BRASIL. Ministério da Educaçáo e Cultura. Lei $\mathrm{n}^{\circ}$ 9.394, de 20 de dezembro de 1996. Estabelece as diretrizes e bases da educação nacional. Diário Oficial [da] República Federativa do Brasil, Brasília, DF, 20 dez. 1996. Disponível em: <http://www.planalto.gov.br/CCIVIL_03/leis/L9394.htm>. Acesso em: 15 mar. 2016.

BRASIL. Ministério da Educação e Cultura. Parecer CNE/CES no 776, de 3 de dezembro de 1997. Diário Oficial [da] República Federativa do Brasil, Brasília, DF, 3 dez. 1997. Disponível em: <http://portal.mec.gov.br/ setec/arquivos/pdf_legislacao/superior/legisla_superior_ parecer77697.pdf>. Acesso em: 15 mar. 2016.

BRASIL. Ministério da Educação e do Desporto. Secretaria de Educação Superior. Comissão de Especialistas de Ensino de Terapia Ocupacional - CEETO. Proposta de Normatização de Diretrizes Curriculares para os Cursos de Terapia Ocupacional. Brasília, 1998.

BRASIL. Ministério da Educação. Reestruturação e Expansäo das Universidades Federais: Diretrizes Gerais. Brasília, 2007a. Disponível em: <http://portal.mec.gov.br/ sesu/arquivos/pdf/diretrizesreuni.pdf>. Acesso em: 15 mar. 2016.

BRASIL. Ministério da Saúde. Ministério da Educação. Programa Nacional de Reorientação da Formação Profissio- nal em Saúde - Pró-Saúde: objetivos, implementaçáo e desenvolvimento potencial. Brasília: Ministério da Saúde, 2007b. Disponível em: <http://www.prosaude.org/ rel/pro_saude1.pdf>. Acesso em: 15 mar. 2016.

BRASIL. Ministério da Saúde. Portaria Interministerial $n^{\circ}$ 421, de 3 de março de 2010. Institui o Programa de Educação pelo Trabalho para a Saúde (PET Saúde) e dá outras providências. Diário Oficial [da] República Federativa do Brasil, Brasília, DF, 5 mar. 2010. Disponível em: $<$ http://bvsms.saude.gov.br/bvs/saudelegis/gm/2010/ pri0421_03_03_2010.html>. Acesso em: 15 mar. 2016.

BRASIL. Ministério de Educação e Cultura. Resolução no 6 do CNE/CES de 19 de fevereiro de 2002. Institui Diretrizes Curriculares Nacionais do Curso de Graduação em Terapia Ocupacional. Diário Oficial [da] República Federativa do Brasil, Brasília, 4 mar. 2002. Disponível em: <http://portal.mec.gov.br/cne/arquivos/pdf/ CES062002.pdf>. Acesso em: 15 mar. 2016.

CARVALHO, C. H. A. Política para o ensino superior no Brasil (1995-2006): ruptura e continuidade nas relaçōes entre público e privado. In: REUNIÃO ANUAL, 30., 2006, Campinas. Anais... Campinas: UNICAMP, 2006. p. 1-16.

CATANI, A. M. O papel da universidade pública hoje: concepção e função. Jornal de Políticas Educacionais, Curitiba, n. 4, p. 4-14, 2008.

CENTRO DE DOCÊNCIA E PESQUISA EM TERAPIA OCUPACIONAL - CDPTO. O Curso de Terapia Ocupacional da Faculdade de Medicina da Universidade de São Paulo. São Paulo, 1997.

CONTERnO, S. F. R. Pressupostos pedagógicos das atuais propostas de formaçāo superior em saúde no Brasil: origens históricas e fundamentos teóricos. 2013. $260 \mathrm{f}$. Tese (Doutorado em Educação) - Universidade Federal de São Carlos, São Carlos, 2013.

CONTERNO, S. F. R.; LOPES, R. E. Inovações do século passado: origens dos referenciais pedagógicos na formação profissional em saúde. Trabalho, Educação e Saúde, Rio de Janeiro, v. 11 n. 3, p. 503-523, 2013.

HAHN, M.S.; LOPES, R. E. Diretrizes para a formaçáo de terapeutas ocupacionais - percursos e perspectivas. Pro-posiçōes, Campinas, v. 14, n. 1(40), p. 121-139, 2003.

INSTITUTO NACIONAL DE ESTUDOS E PESQUISAS EDUCACIONAIS ANÍSIO TEIXEIRA INEP. Cadastro e-MEC de Instituiçôes e Cursos de Educação Superior. Brasília, 2013. Disponível em: <http:// emec.mec.gov.br/>. Acesso em: 04 jun. 2013.

LÉDA, D. B.; MANCEBO, D. REUNI: Heteronomia e precarizaçáo da universidade e do trabalho docente. Educação e Realidade, Porto Alegre, v. 34, n. 1, p. 49-64, 2008.

LOPES, R. E. A formação do terapeuta ocupacional -o curriculo: histórico e propostas alternativas. 1991. 215 
f. Dissertação (Mestrado em Educação) - Universidade Federal de São Carlos, São Carlos, 1991.

LOPES, R. E. A formação do terapeuta ocupacional: consideraçóes sobre a trajetória de 50 anos no Brasil. In: CONGRESSO NORTE-NORDESTE DE TERAPIA OCUPACIONAL, 5., 2004, Fortaleza. Anais..., Fortaleza, 2004.

LOPES, R. E. et al. II Seminário Nacional de Pesquisa em Terapia Ocupacional. Revista de Terapia Ocupacional da Universidade de São Paulo, São Paulo, v. 25, n. 2, p. 167-76, 2014.

LOPES, R. E. et al. XI Encontro Nacional de Docentes de Terapia Ocupacional: refletindo sobre os processos de formação acadêmica e profissional. Revista de Terapia Ocupacional da Universidade de São Paulo, São Paulo, v. 19, n. 3, p. 159-166, 2008.

LOPES, R. E.; MAGALHÂES, L. V.; MAGALHĀES, L. C. Comissão de Especialistas de Ensino de Terapia
Ocupacional. Revista de Terapia Ocupacional da Universidade de São Paulo, São Paulo, v. 12, n. 1/3, p. 9-9, 2001.

REDE NACIONAL DE ENSINO E PESQUISA EM TERAPIA OCUPACIONAL - RENETO. Proposta de Normatização de Diretrizes Curriculares para os Cursos de Terapia Ocupacional. São Paulo, 1998. Arquivos RENETO.

REDE NACIONAL DE ENSINO E PESQUISA EM TERAPIA OCUPACIONAL -RENETO. Carta de manifestação junto à Câmara de Educação Superior do Conselho Nacional de Educação. São Paulo, 2008. Arquivos RENETO.

SOARES, L. B. T. Terapia Ocupacional: lógica do capital ou do trabalho. São Paulo: Hucitec, 1991.

WORLD FEDERATION OF OCCUPATIONAL THERAPY - WFOT. Normas minimas revisadas para laformación de terapeutas ocupacionales. Australia, 2002.

\section{Contribuição dos Autores}

Ambas autoras foram responsáveis pela redação do texto e aprovaram a versão final do artigo.

\section{Fonte de Financiamento}

FAPESP - Processo no 2012/13593-7

\section{Notas}

${ }^{1}$ Este texto toma como referência a Dissertação de Mestrado "Políticas de Ensino Superior, Graduação em Terapia Ocupacional e o Ensino de Terapia Ocupacional Social no Brasil”, apresentada ao Programa de Pós-Graduação em Terapia Ocupacional da Universidade Federal de São Carlos e que contou com o apoio da Fundaçáo de Amparo à Pesquisa do Estado de São Paulo (FAPESP) - Processo nº 2012/13593-7.

${ }^{2}$ Que condicionava o acesso a recursos materiais e humanos à adesão das Instituiçôes de Ensino Superior a tais programas.

${ }^{3}$ Ilka Falcão e Selma Lancman, ainda na comissão conjunta com a fisioterapia (1995-1997); Selma Lancman, Amélia Pessoa e Sandra Galheigo (1997-1999), Lilian Magalhães, Lívia Magalhães e Roseli Lopes (1999-2001). A partir de 2002, essa comissão passou a se denominar Comissão Assessora de Avaliação da Área de Terapia Ocupacional e ficou vinculada, como todas as demais, ao Instituto Nacional de Estudos e Pesquisas Educacionais Anísio Teixeira - INEP/MEC. Foram membros dessa última comissão as docentes: Ana Cláudia Lima, Marcella Assis; Maria Auxiliadora Ferrari, Marta de Almeida, Michelle Hahn, Roseli Lopes, Sandra Galheigo (2004-2006), Ana Cláudia Lima, Kátia Bueno, Marcella Assis, Maria Auxiliadora Ferrari, Rose Toldrá, Roseli Lopes e Sandra Galheigo (2007-2010), Ana Cláudia Lima, Katia Bueno, Marcella Assis, Maria Auxiliadora Ferrari, Rita Pereira, Roseli Lopes e Sandra Galheigo (2010-2012).

${ }^{4}$ Desde 1986, é realizado a cada dois anos o Encontro Nacional de Docentes de Terapia Ocupacional - ENDTO. Sua primeira edição foi em Belo Horizonte-MG e a última, o XIV ENDTO, foi em João Pessoa-PB. Nas diversas edições do evento, o tema da formaçăo profissional graduada é uma constante (LOPES et al., 2008).

${ }^{5}$ Em 2014 e 2015, assistimos a uma série de aberturas de concursos públicos para vagas docentes efetivas junto a diversos desses cursos.

${ }^{6}$ Neste período, houve também a criação do Curso de Graduação em Terapia Ocupacional do Instituto Federal do Rio de Janeiro, o qual compôs o universo dos cursos aqui estudados; contudo, a sua implantaçáo foi oportunizada pelo processo de transformação dos Centros Federais de Educação Tecnológica em Institutos Federais de Educação Ciência e Tecnologia, passando a oferecer também cursos de nível superior (BRASIL, 2008).

${ }^{7}$ Entender por que, mesmo com o REUNI, algumas IFES de importantes estados da federação permaneceram sem a oferta de cursos nessa área é um estudo a ser feito. 